\title{
Retrospective analysis of hospital discharge records for cases of trichinellosis does not allow evaluation of disease burden in Italy
}

\author{
Edoardo Pozio ${ }^{1}$, Alessandra Ludovisi ${ }^{1}$, Patrizio Pezzotti ${ }^{1}$, Fabrizio Bruschi ${ }^{2}$, and Maria Ángeles Gómez-Morales ${ }^{1, *}$ \\ ${ }^{1}$ Department of Infectious Diseases, Istituto Superiore di Sanità, viale Regina Elena 299, 00161 Rome, Italy \\ ${ }^{2}$ Department of Translational Research, N.T.M.S. Università di Pisa, via Roma 55, 56126 Pisa, Italy
}

Received 17 April 2019, Accepted 27 June 2019, Published online 16 July 2019

\begin{abstract}
Human trichinellosis is a disease caused by nematode worms of the genus Trichinella. In Italy, as well as in most other European countries, notification of Trichinella infections in humans is mandatory; however, no information is available on the number of cases occurring annually. The aim of the present study was to retrospectively evaluate the burden of trichinellosis in Italy from 2005 to 2016. Hospital discharge records (HDRs) showing the code for trichinellosis (124) were registered and screened. Results were then compared with yearly reports issued by the Italian National Reference Laboratory for Trichinella (NRLT), with reports from the European Centre for Disease Prevention and Control (ECDC), and with literature data. A total of 102 HDRs revealed that the 124 code was erroneously reported in $72(70.6 \%)$ records. Out of the $30(29.4 \%)$ records with a correct diagnosis of trichinellosis, nine cases were reported by HDRs only, 21 cases were documented by both HDRs and the NRLT, whereas the NRLT documented 100 additional cases. In the studied period, the average yearly incidence was 0.01 cases per 100,000 inhabitants. This study highlights the limitations of using HDRs to obtain a clear picture of the prevalence and incidence of trichinellosis in Italy. These findings demonstrate the need to intensify the surveillance system for trichinellosis through the development of an Italian registry. This would allow the identification of patients with severe infections and pauci-symptomatic patients, and would avoid the need for clinical analyses and unnecessary treatments, reducing the resulting economic burden on the Italian National Health Service.
\end{abstract}

Key words: Trichinella, Hospital discharge records, Epidemiology, Italy, Prevalence, Incidence.

Résumé - L'analyse rétrospective des dossiers de sortie de l'hôpital relatifs à la trichinellose ne permet pas d'évaluer la charge de la maladie en Italie. La trichinellose humaine est une maladie causée par les nématodes du genre Trichinella. En Italie, ainsi que dans la plupart des autres pays Européens, la notification des infections à Trichinella chez l'homme est obligatoire, mais aucune information n'est disponible sur le nombre de cas survenant chaque année. La présente étude visait à évaluer de manière rétrospective la charge de la trichinellose en Italie de 2005 à 2016. Les dossiers de sortie d'hôpital (DSH) indiquant le code de la trichinellose (124) ont été enregistrés et examinés. Les résultats ont ensuite été comparés aux rapports annuels du Laboratoire national de référence italien pour Trichinella (NRLT), du Centre européen de prévention et de contrôle des maladies (ECDC) et aux données de la littérature. L'analyse des 102 dossiers de sortie a montré que le code 124 avait été utilisé par erreur pour 72 dossiers (70,6 \%). Parmi les 30 dossiers $(29,4 \%)$ avec un diagnostic correct de trichinellose, neuf cas avaient été identifiés seulement par le DSH et 21 cas à la fois par le DSH et par le NRLT. Sur la même période, le NRLT avait documenté 100 cas supplémentaires. Au cours de la période de l'étude, l'incidence annuelle moyenne était de 0,01 cas pour 100000 habitants. Cette étude a mis en évidence les limites de l'utilisation des DSH pour obtenir une image fidèle de la prévalence et de l'incidence de la trichinellose en Italie. Cette étude identifie la nécessité d'intensifier le système de surveillance de la trichinellose par la mise en place d'un registre italien. Cela permettrait d'identifier les patients pauci-symptomatiques ou atteints d'infections sévères, et éviterait le recours à des analyses cliniques et à des traitements inutiles, ce qui réduirait la charge économique qui en résulte pour le Service National de Santé italien.

\section{Introduction}

Trichinellosis is a cosmopolitan infectious disease caused by nematode parasites of the genus Trichinella. Human infection occurs through the ingestion of muscle-encysted larvae in raw or semi-raw meat and meat products derived from pigs, horses and wild omnivorous and/or carnivorous animals [31]. A systematic review of the scientific literature

\footnotetext{
*Corresponding author: mariaangeles.gomezmorales@iss.it
}

This is an Open Access article distributed under the terms of the Creative Commons Attribution License (http://creativecommons.org/licenses/by/4.0), which permits unrestricted use, distribution, and reproduction in any medium, provided the original work is properly cited. 
on worldwide cases of human trichinellosis published between 1986 and 2009 showed that the majority of infections $(56,912$; $86.47 \%$ ) were recorded in Europe [35]. Trichinellosis can be severe when the infecting dose is high, particularly in the elderly, who may develop complications such as myocarditis or encephalitis possibly leading to death $[9,10,33]$.

The number of trichinellosis cases within the European Union (EU) increased during the 1970s and until the end of the 1990s due to the growing prevalence of Trichinella spp. infections in domestic pigs of Eastern European origin (Bulgaria, Poland and Romania), and the occurrence of large outbreaks caused by the consumption of horse meat imported into France and Italy from Eastern Europe and other regions (Canada, Mexico and the United States) [4, 36, 37]. The prevalence of trichinellosis in Europe slowly decreased following the implementation of control programs in pig husbandry and the disappearance of Trichinella infections caused by horse meat consumption, following the introduction of controls at the abattoir [11, 12].

In Italy, trichinellosis was documented for the first time in 1887; only four sporadic cases and an outbreak with two deaths were recorded in Central and Northern Italy up to 1930 [8]. From 1933 to 1946, four large outbreaks involving 209 patients with 22 deaths occurred in Sicily through the consumption of infected pig meat [38]. After World War II to the year 2000, 1383 cases in the context of 22 outbreaks, and about 70 single cases, were documented to have been caused by the consumption of infected pig, horse or wild boar meat or meat-derived products [8, 39]. From 2001 to 2004, 12 infections, two of which were acquired abroad (Croatia), were documented in the context of three outbreaks [41] (Pozio E., unpublished data). Although trichinellosis is a notifiable disease in Italy, the real prevalence and incidence is unknown due to the absence of pathognomonic signs and symptoms, and the lack of highly sensitive and specific laboratory tests available on the market.

The aim of the present study was to retrospectively evaluate the burden of trichinellosis in Italy from 2005 to 2016, based on hospital discharge records (HDRs). The results of HDRs were compared with yearly reports issued by the Italian National Reference Laboratory for Trichinella (NRLT) and those of the European Centre for Disease Prevention and Control (ECDC), as well as with literature data.

\section{Materials and methods}

The Italian hospital information system (Ihis), established in 1995, routinely collects data on all public and private hospital discharges and covers $100 \%$ of hospital admissions in Italy [2]. Ihis systematically collects both demographic and clinical information, including primary diagnosis and up to five subsequent diagnoses, primary and secondary diagnostic/therapeutic procedures, and length of hospital stay. Diagnoses and procedures are coded using the "International Classification of Diseases, 9th Revision, Clinical Modification" (ICD-9-CM) [32]. The data are sent by hospitals to the Regional Health Authority that is responsible for data quality verification before communicating the information to the Italian Ministry of Health.

The HDRs contain an anonymous individual code for tracking the patient's hospital admissions, discharges and readmissions. Each anonymous individual code identifies one patient. Data from HDRs for the period from 2005 to 2016 were used. Hospital discharges were selected on the basis of the ICD-9-CM code 124 for trichinellosis, when indicated in a primary or secondary diagnosis. Information retrieved included hospital code, name and address of the hospital, patient code, gender, region, place of residence, trichinellosis diagnosis if reported as the primary or secondary diagnosis, and hospital admission and discharge dates.

In January 2018, details of the retrospective project were emailed to the 54 hospitals registered within the health system of the Italian Ministry of Health as having patient admissions with the ICD-9-CM code 124. Hospitals were invited to submit a hard or electronic copy of anonymized patient records for which individual codes were available to the Department of Infectious Diseases at the Istituto Superiore di Sanità (Italian National Institute of Health). The deadline for record forwarding was set as April 15, 2018. In addition, if patient sera were still available, hospitals were invited to ship samples to the NRLT for confirmation of positive serology. This project was approved by the Istituto Superiore di Sanità ethics committee (Prot. PRE-18/18 of January 11, 2018).

The screening of medical records was based on the ECDC case definition [13] and the algorithm proposed by DupouyCamet and Bruschi [9]. The number of trichinellosis cases was then compared with trichinellosis infections documented by the NRLT, ECDC and the international literature for the same time period.

Sera forwarded by hospitals to the NRLT were tested with a validated ELISA using excretory/secretory (ES) antigens as a first screening assay, and ELISA-positive sera were confirmed by a validated Western blot using ES antigens [29, 30].

\section{Results}

During the period between 2005 and 2016, a total of 102 HDRs showing the trichinellosis 124 code were registered. All hospitals provided the requested medical records in electronic or hardcopy forms. Within this group, diagnosis of trichinellosis was reported either as the principal diagnosis or as the secondary diagnosis (up to the fifth level of secondary diagnosis). The screening of 102 records revealed that the 124 code was erroneously reported in 72 (70.6\%) records provided by 42 hospitals as detailed in Table 1 . Four serum samples, which had tested positive for Trichinella by commercial kits at hospital laboratories and sent together with the HDRs to our laboratory, tested negative by the validated serological tests used at the NRLT.

Out of $30(29.4 \%)$ records with a correct diagnosis of trichinellosis on the basis of the ECDC case definition, five patients had acquired the infection in Romania and developed the disease in Italy from 2006 and 2013, and one patient acquired trichinellosis through the consumption of pork 
Table 1. Features of hospital discharge records (HDRs) with the 124 code (for trichinellosis) downloaded from the Italian Ministry of Health website for the period 2005-2016.

\begin{tabular}{lr}
\hline HDR features & No. (\%) \\
\hline Records with the 124 code erroneously reported due to: & $72(70.6)$ \\
- Typing errors & $43(42.1)$ \\
- Use of a new HDR code for the hospital readmission of trichinellosis cases at follow-up & $8(7.8)$ \\
- Inadequate diagnostic tools ${ }^{\mathrm{a}}$ & $5(4.9)$ \\
- Presence of only eosinophilia & $5(4.9)$ \\
- Absence of clarity between the genus name Trichuris and Trichinella & $4(3.9)$ \\
- Serum sample(s) tested by unreliable commercial kit & $4(3.9)$ \\
- Absence of clarity between trichilemmoma and trichinellosis & $2(1.9)$ \\
- Absence of clarity between trichiasis and trichinosis & $1(0.9)$ \\
Records correctly reporting the 124 code & $30(29.4)$ \\
Total records & $102(100)$ \\
\hline
\end{tabular}

${ }^{a}$ Copromicroscopic test of fecal samples (three patients, one of whom with Trichuris trichiura eggs); colonoscopy with biopsy (one patient) and without biopsy (one patient).

imported into Italy in 2009 from Romania. Four patients had acquired trichinellosis by the consumption of wild boar meat in different regions of the country. From 2005 to 2007, 19 patients had acquired trichinellosis through the consumption of pork in the Sardinia region. A trichinellosis infection was documented in Ancona hospital (Marche region, Central Italy) in 2005, but no information on the source of infection was available (Table 2).

Discrepancies were observed between data provided by HDRs, the NRLT and ECDC (Table 2). From 2005 to 2016, there were 130 reported cases of trichinellosis in Italy, of which 9 were documented by HDRs only, 21 by both HDRs and the NRLT, and 100 by the NRLT only. Of the 130 documented infections, the Italian Ministry of Health provided only 86 $(66.1 \%)$ cases to the ECDC (Table 2). The nine cases documented only by HDRs included a small outbreak involving two patients, and seven single cases of which six were acquired abroad (Romania), and one acquired in Italy. The examination of the NRLT reports and/or published data for the period between 2005 and 2016 showed that 54 (39.7\%) patients were hospitalized, whereas only $30(54.5 \%)$ hospitalized patients were documented by HDRs (Table 2). During the investigated 12 -year period, the average annual incidence was 0.01 cases per 100,000 inhabitants (range 0.001-0.06).

Information on the etiological agents of trichinellosis cases was available in $98.4 \%$ of cases. Trichinella britovi was documented in $65.4 \%$ of infections, Trichinella pseudospiralis in $23.0 \%$, and Trichinella spiralis in $10.0 \%$ (Table 2). All the $T$. spiralis-infected patients had eaten meat from animals reared abroad whose meat was either consumed abroad or was imported illegally (pork) into Italy, where the meat was subsequently consumed raw.

In the period under study, the main source of infection was meat and meat-derived products of illegally hunted wild boar $(63.0 \%)$, followed by free-ranging pigs (20.0\%), pork consumption in Romania $(7.7 \%)$, horse meat imported from abroad (5.4\%), and pork imported from Romania (3.0\%) (Table 2). No information was available on the source of infection of a single case $(0.8 \%)$, which was diagnosed in Ancona (Marche region) in 2005.

\section{Discussion}

The examination of patient records with the ICD-9-CM code 124, issued in a 12-year period (2005-2016), showed that in most cases $(n=72 ; 70.6 \%)$ the code had been erroneously assigned as a result of typing errors ( $n=43,42.1 \%)$, the use of a new patient code $(n=8 ; 7.8 \%)$ at the time of readmission of trichinellosis cases for follow-up, the use of inappropriate diagnostic methods (e.g., detection of "parasites" in fecal samples or colonoscopy) $(n=5,4.9 \%)$, poor knowledge of case definition $(n=10,9.8 \%)$, absence of clarity with regards to worm terminology (Trichuris versus Trichinella) $(n=4$, $3.9 \%)$, the use of invalidated serological kits $(n=4,3.9 \%)$, and misspelling of the disease during reporting $(n=3,2.9 \%)$ (Table 1).

Excluding typing errors and the use of different codes for the same patient, 21 (20.6\%) inaccurate diagnoses were probably related to the lack of expertise regarding human trichinellosis seen at the hospital level. This may be due to both the rarity of the disease and the lack of emphasis on including diseases caused by helminths within the curricula of the majority of Italian Medical Faculties [6].

Within the EU, the notification of human Trichinella is mandatory in all countries, except for Belgium, France, and the United Kingdom which possess voluntary surveillance systems. In contrast, no surveillance system for trichinellosis exists in Denmark [25]. From 2005 to 2016, the trend for trichinellosis in the EU was greatly influenced by several outbreaks, with peaks often occurring through January and February. According to the ECDC, the annual number of trichinellosis cases documented in the EU decreased from 867 in 2007 to 224 in 2017 [26]. This reduction in human infections of about $75 \%$ is mainly due to improvements in pig rearing practices in Eastern European countries (Bulgaria, Croatia and Romania), increased control measures at the slaughterhouse, and the education of consumers, farmers and butchers on methods of transmission and prevention.

The occurrence in Italy during the period 2005-2016 of 14 cases of trichinellosis $(10.7 \%$ of the total number of cases documented in Italy in the investigated period) with infection 
Table 2. Human trichinellosis cases documented in Italy from 2005 to 2016 according to hospital discharge records (HDRs), surveillance by the National Reference Laboratory for Trichinella (NRLT), and ECDC reports.

\begin{tabular}{|c|c|c|c|c|c|}
\hline Year & $\begin{array}{l}\text { Locality } \\
\text { (region) }\end{array}$ & $\begin{array}{l}\text { No. of cases } \\
\text { according } \\
\text { to HDRs }\end{array}$ & $\begin{array}{c}\text { No. of cases } \\
\text { according to NRLT } \\
\text { (No. of hospitalized } \\
\text { patients) }\end{array}$ & $\begin{array}{l}\text { Source of infection } \\
\text { (etiological agent) }^{\mathrm{a}}\end{array}$ & $\begin{array}{l}\text { No. of cases per year } \\
\text { according to ECDC }\end{array}$ \\
\hline \multirow[t]{5}{*}{2005} & Ancona (Marche) & 1 & n.d. ${ }^{\mathrm{c}}$ & Unknown & \multirow{5}{*}{$\begin{array}{l}\text { Italy did not provide } \\
\text { any information }\end{array}$} \\
\hline & Avezzano (Abruzzo) & 2 & n.d. & Hunted wild boar $(\mathrm{Tb})$ & \\
\hline & Cagliari (Sardinia) ${ }^{\mathrm{d}}$ & 4 & $5(4)$ & Free ranging pig $(\mathrm{Tb})$ & \\
\hline & Nuoro $(\text { Sardinia })^{\mathrm{d}}$ & 8 & $8(8)$ & Free ranging pig $(\mathrm{Tb})$ & \\
\hline & Mantua (Lombardy) ${ }^{\mathrm{e}}$ & n.d. & $7(7)$ & Horse meat imported from Belgium $(\mathrm{Tb})$ & \\
\hline \multirow[t]{3}{*}{2006} & Verona (Veneto) & 1 & n.d. & Pork consumption in Romania (Ts) & \multirow{3}{*}{$\begin{array}{l}\text { Italy did not provide } \\
\text { any information }\end{array}$} \\
\hline & Nuoro (Sardinia) ${ }^{\mathrm{f}}$ & $6^{\mathrm{g}}$ & $6(6)$ & Free ranging pig $(\mathrm{Tb})$ & \\
\hline & Lombardy & n.d. & $3(3)$ & Imported pork from Romania (Ts) & \\
\hline 2007 & Nuoro $(\text { Sardinia })^{g}$ & 1 & $1(1)$ & Free ranging pig $(\mathrm{Tb})$ & 1 \\
\hline \multirow[t]{2}{*}{2008} & Tortona (Piedmont) & 1 & n.d. & Pork consumption in Romania (Ts) & \multirow{2}{*}{$\begin{array}{l}\text { Italy did not provide } \\
\text { any information }\end{array}$} \\
\hline & Verona $(\text { Veneto })^{\mathrm{h}}$ & n.d. & $4(4)$ & Pork consumption in Romania (Ts) & \\
\hline \multirow[t]{2}{*}{2009} & Cuneo (Piedmont) ${ }^{\mathrm{i}}$ & 1 & $6(1)$ & Hunted wild boar (Tb) & \multirow[t]{2}{*}{1} \\
\hline & Verona (Veneto) & 1 & n.d. & Imported pork from Romania (Ts) & \\
\hline 2010 & Monza (Lombardy) & 1 & n.d. & Pork consumption in Romania & 0 \\
\hline 2011 & Nuoro $(\text { Sardinia) })^{\mathrm{j}}$ & n.d. & $6(6)$ & Free ranging pig $(\mathrm{Tb})$ & 6 \\
\hline \multirow[t]{2}{*}{2012} & Valle del Serchio (Tuscany) ${ }^{\mathrm{k}}$ & 1 & $34(6)$ & Hunted wild boar (Tb) & \multirow[t]{2}{*}{33} \\
\hline & Treviso (Friuli Venezia Giulia) & 1 & n.d. & Pork consumption in Romania (Ts) & \\
\hline 2013 & Torino (Piedmont) & 1 & n.d. & pork consumption in Romania (Ts) & $\begin{array}{l}\text { Italy did not provide } \\
\text { any information }\end{array}$ \\
\hline 2014 & Latronico (Basilicata) & n.d. & $4(1)$ & Hunted wild boar $(\mathrm{Tb})$ & 4 \\
\hline 2015 & Genova (Liguria) & n.d. & $30(4)$ & Suspected hunted wild boar (Tp) & $36^{1}$ \\
\hline 2016 & Manfredonia (Apulia) ${ }^{\mathrm{m}}$ & n.d. & $5(1)$ & Hunted wild boar $(\mathrm{Tb})$ & 5 \\
\hline 2016 & Pescara $(\text { Abruzzo })^{\mathrm{n}}$ & n.d. & $1(1)$ & Pork consumption in Romania (Ts) & \\
\hline 2016 & Mattinata (Apulia) & n.d. & $1(1)$ & Hunted wild boar $(\mathrm{Tb})$ & \\
\hline Total & & 30 & $121(54)$ & & $86^{\mathrm{k}}$ \\
\hline
\end{tabular}

${ }^{\mathrm{a}} \mathrm{Ts}=$ Trichinella spiralis $; \mathrm{Tb}=$ Trichinella britovi $; \mathrm{Tp}=$ Trichinella pseudospiralis. ${ }^{\mathrm{b}}\left[\right.$ [14-25]. ${ }^{\mathrm{c}} \mathrm{n} . \mathrm{d} .=$ not documented. ${ }^{\mathrm{d}}$ [42]. ${ }^{\mathrm{e}}$ [37]. ${ }^{\mathrm{f}}[40]$.

${ }^{\mathrm{g}}$ Eight additional HDRs refer to the follow-up of the same patients. ${ }^{\mathrm{h}}$ [1]. ${ }^{\mathrm{i}}[43] .{ }^{\mathrm{j}}$ [3]. ${ }^{\mathrm{k}}$ [27]. ${ }^{\mathrm{l}}$ Six persons with positive serology did not meet the ECDC case definition of trichinellosis. ${ }^{\mathrm{m}}$ [44]. ${ }^{\mathrm{n}}$ [28].

links originating from Romania is not surprising. Within the EU, Romania continues to represent the main focus of Trichinella infections among domestic pigs [26]. Seven infections occurred in Mantua (Lombardy region, Northern Italy) through the consumption of horse meat imported from abroad [37]. The 26 cases documented in two hospitals in Sardinia refer to four outbreaks and a single case, which occurred in 2005, 2006, 2011 and a single case in 2007. All these infections were caused by the consumption of raw meat from illegally slaughtered free-ranging pigs [3, 34, 40, 42]. The case of hospitalization in Lucca province (Tuscany region, Central Italy) refers to the index patient of an outbreak of trichinellosis, which involved 34 patients who had consumed raw sausages made with meat from a hunted wild boar in 2012 [27]. Another case was the index patient of an outbreak that involved six individuals who had consumed raw meat of a hunted wild boar in Cuneo province (Piedmont region, Northern Italy) in 2009 [43].

No HDRs were available for six outbreaks of trichinellosis involving 59 patients, 26 of whom were hospitalized and two single cases for which the NRLT performed serological tests and epidemiological investigations from 2005 to 2016 (Table 2).

From 2005 to 2016, trichinellosis infections were documented in 11 out of 20 Italian regions, without substantial differences between northern, central and southern Italy (Fig. 1).
However, it is noteworthy that in 13 of the 14 trichinellosis cases, infection was acquired abroad (Romania) and illness developed in Italy, or they were caused through the consumption in Italy of pork from Romania illegally imported into Northern Italy, where about $50 \%$ of Romanian immigrants present in Italy live [45].

This study shows the limitation of the use of HDRs to obtain information on trichinellosis in Italy, as was already shown for other nematode infections, namely echinococcosis and anisakidosis [5, 7]. Since patients with severe or moderately severe trichinellosis quite frequently develop cardiovascular and neurological symptoms, as well as other complications, they could be discharged with an HDR code not indicating trichinellosis but other diseases. The number $(n=33,25.4 \%)$ of inpatients with confirmed trichinellosis documented by the NRLT, but not by HDRs, strongly supports this hypothesis. In addition, during the course of a trichinellosis outbreak, only a low percentage of infected patients are hospitalized and this number is related not only to the severity of the infection, but also to the expertise of the physician and to different policies for hospitalization in different regions of Italy. It therefore follows that some patients access hospitals as outpatients for blood collection and treatment, but are neither reported nor registered by HDRs. 


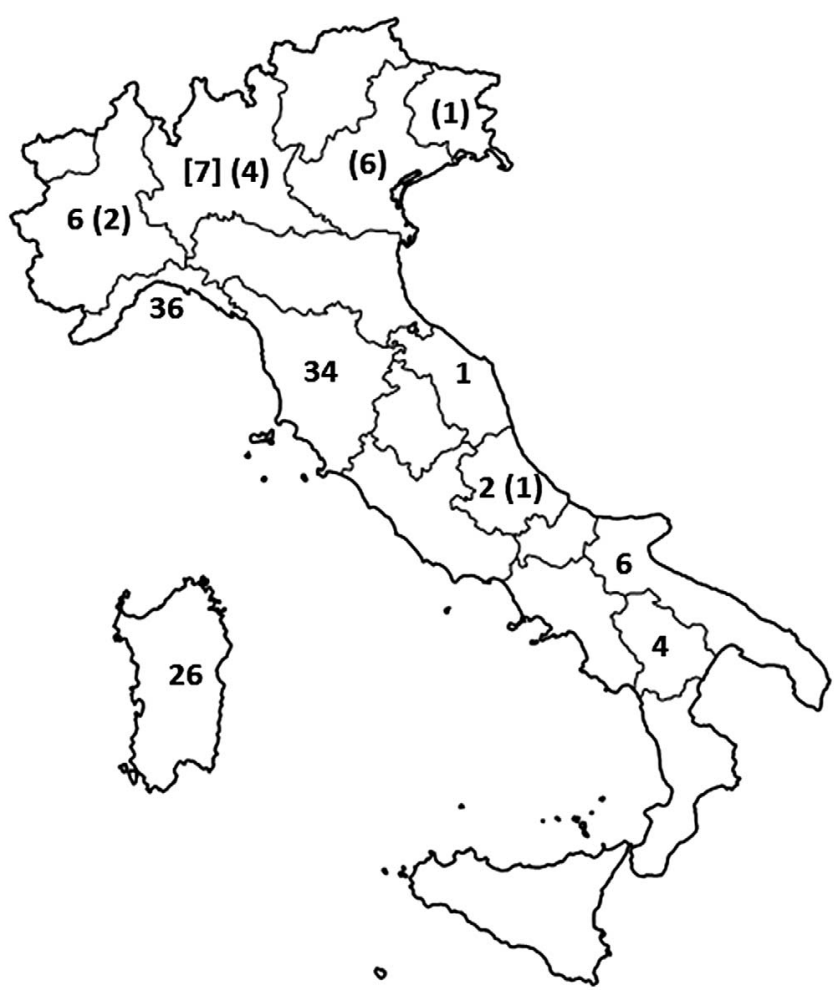

Figure 1. Distribution per region of trichinellosis cases documented in Italy from 2005 to 2016. Numbers in brackets are infections acquired in Romania and developed in Italy, or acquired in Italy through the consumption of illegally imported pork from Romania. The number in square brackets refers to trichinellosis cases acquired through the consumption of horse meat imported from Belgium.

In addition, the retrospective retesting of serum samples, tested positive for Trichinella infection at the hospital laboratory, but not confirmed at the NRLT, emphasizes the low specificity of commercial kits, primarily due to the use of crude antigens that cross-react with other parasitic and non-parasitic antigens [29, 30].

The reduction in prevalence of parasitic diseases in industrialized countries in the 20th century resulted in the loss of diagnostic expertise among physicians, microbiologists and biologists. Additionally, meaningful investments in the development of new diagnostic tools for parasitic diseases remain scarce. A plethora of commercial kits for the diagnosis of parasitic infections, including trichinellosis, is on the market; however, most of these kits have not been validated by an independent body, resulting in poor diagnostic power. Furthermore, in Italy, due to financial constraints, some diagnostic laboratories purchase the cheapest commercial kits without taking into consideration their performance.

The results of the present study show that the surveillance system of the NRLT lost only $6.6 \%$ of trichinellosis infections that occurred in the studied period, whereas HDRs do not provide useful epidemiological information for this disease. This study suggests the need to develop an Italian registry on trichinellosis and to collect and disseminate information on the clinical and laboratory patterns, the long incubation time, and seroconversion times of this zoonotic disease. This information will support physicians for a diagnosis of choice and public health services to carry out epidemiological investigations during the course of trichinellosis outbreaks. The identification not only of patients with severe infections, but also of paucisymptomatic patients, will eliminate the need for clinical analyses and unnecessary treatments, and thus help reduce the resulting economic burden on the Italian National Health Service.

Acknowledgements. This work was supported by the Italian Ministry of Health - CCM: azioni centrali-, programma CCM 2016 "Analisi epidemiologica di tre malattie infettive orfane: Trichinella, Listeria, Echinococcus". We kindly thank Belgees Boufana for reviewing the manuscript. We thank the Italian Ministry of Health for providing the HDR data ("Banca Dati SDO - Ministero della Salute") as agreed with the "Accordo di Collaborazione tra Ministero della Salute e ISS per l'utilizzo del flusso informativo di dimissioni ospedaliere per condurre studi in Sanità Pubblica". We are also very grateful to hospital personnel who provided us with patient records with the ICD-9-CM code 124 (trichinellosis).

\section{Conflict of interest}

The authors declare that they have no conflict of interest.

\section{References}

1. Angheben A, Mascarello M, Zavarise G, Gobbi F, Monteiro G, Marocco S, Anselmi M, Azzini A, Concia E, Rossanese A, Bisoffi Z. 2008. Outbreak of imported trichinellosis in Verona, Italy, January 2008. Eurosurveillance, 13(22), 18891.

2. Anonymous. 2008. La scheda di dimissione ospedaliera (Hospital discharge records). Available from: http://www. salute.gov.it/portale/temi/p2_6.jsp?lingua=italiano\&id=1232 $\&$ area=ricoveriOspedalieri\&menu=vuoto). Accessed 30 April 2018.

3. Bandino E, Goddi L, Mulas M, Murgia MC, Soddu M, Marucci G, Pezzotti P, Cabras PA, Pozio E. 2015. Trichinella britovi from domestic to wild animals of Sardinia, Italy. Veterinary Parasitology, 212(3-4), 262-266.

4. Blaga R, Durand B, Antoniu S, Gherman C, Cretu CM, Cozma V, Boireau P. 2007. A dramatic increase in the incidence of human trichinellosis in Romania over the past 25 years: impact of political changes and regional food habits. American Journal of Tropical Medicine and Hygiene, 76(5), 983-986.

5. Brundu D, Piseddu T, Stegel G, Masu G, Ledda S, Masala G. 2014. Retrospective study of human cystic echinococcosis in Italy based on the analysis of hospital discharge records between 2001 and 2012. Acta Tropica, 140, 91-96.

6. Bruschi F. 2009. How parasitology is taught in medical faculties in Europe? Parasitology, lost? Parasitology Research, 105(6), 1759-1762.

7. Cavallero S, Martini A, Migliara G, De Vito C, Iavicoli S, D'Amelio S. 2018. Anisakiasis in Italy: analysis of hospital discharge records in the years 2005-2015. PLoS One, 13, e0208772.

8. de Carneri I, Di Matteo L. 1989. Epidemiology of trichinellosis in Italy and in neighboring countries. Annali dell'Istituto Superiore di Sanità, 25, 625-633.

9. Dupouy-Camet J, Bruschi F. 2007. Management and diagnosis of human trichinellosis, in FAO/WHO/OIE guidelines for the surveillance, management, prevention and control of trichinellosis, Dupouy-Camet J, Murrell KD, Editors. 1st edn. FAO/ WHO/OIE: Paris, France. p. 37-68. 
10. Dupouy-Camet J, Kociecka W, Bruschi F, Bolas-Fernandez F, Pozio E. 2002. Opinion on the diagnosis and treatment of human trichinellosis. Expert Opinion on Pharmacotherapy, 3(8), 1117-1130.

11. Commission European. 2005. Regulation (EC) No. 2075/2005 of the European Parliament and of the Council of 5 December 2005 laying down specific rules on official controls for Trichinella in meat. Official Journal of the European Union Legislation, 338, 60-82.

12. European Commission. 2015. Commission implementing regulation 2015/1375 of 10 August 2015 laying down specific rules on official controls for Trichinella in meat. Official Journal of the European Commission Legislation, 212, 7-34.

13. European Commission. 2018. Commission implementing decision (eu) 2018/945 on the communicable diseases and related special health issues to be covered by epidemiological surveillance as well as relevant case definitions. Official Journal of the European Union Legislation, 170, 1-74.

14. European Food Safety Agency. 2006. The community summary report on trends and sources of zoonoses, zoonotic agents, antimicrobial resistance and foodborne outbreaks in the European Union in 2005. EFSA Journal, 94, 2-288.

15. European Food Safety Agency. 2007. The community summary report on trends and sources of zoonoses, zoonotic agents, antimicrobial resistance and foodborne outbreaks in the European Union in 2006. EFSA Journal, 130, 2-352.

16. European Food Safety Agency. 2009. Trends and sources of zoonoses and zoonotic agents in the European Union in 2007. EFSA Journal, 223, 3-320.

17. European Food Safety Agency. 2010. Trends and sources of zoonoses and zoonotic agents and food-borne outbreaks in the European Union in 2008. EFSA Journal, 8, 1496.

18. European Food Safety Agency. 2011. The European Union summary report on trends and sources of zoonoses, zoonotic agents and food-borne outbreaks in 2009. EFSA Journal, 9, 2090.

19. European Food Safety Agency. 2012. The European Union summary report on trends and sources of zoonoses, zoonotic agents and food-borne outbreaks in 2010. EFSA Journal, 10, 2597.

20. European Food Safety Agency. 2013. The European Union summary report on trends and sources of zoonoses, zoonotic agents and food-borne outbreaks in 2011. EFSA Journal, 11, 3129.

21. European Food Safety Agency. 2014. The European Union summary report on trends and sources of zoonoses, zoonotic agents and food-borne outbreaks in 2012. EFSA Journal, 12, 3547.

22. European Food Safety Agency. 2015a. The European Union summary report on trends and sources of zoonoses, zoonotic agents and food-borne outbreaks in 2013. EFSA Journal, 13, 3991.

23. European Food Safety Agency. 2015b. The European Union summary report on trends and sources of zoonoses, zoonotic agents and food-borne outbreaks in 2014. EFSA Journal, 13, 4329.

24. European Food Safety Agency. 2016. The European Union summary report on trends and sources of zoonoses, zoonotic agents and food-borne outbreaks in 2015. EFSA Journal, 14, 4634.

25. European Food Safety Agency. 2017. The European Union summary report on trends and sources of zoonoses, zoonotic agents and food-borne outbreaks in 2016. EFSA Journal, 15, 5077.

26. European Food Safety Agency. 2018. The European Union summary report on trends and sources of zoonoses, zoonotic agents and food-borne outbreaks in 2017. EFSA Journal, 16, 5500 .

27. Fichi G, Stefanelli S, Pagani A, Luchi S, De Gennaro M, Gómez-Morales MA, Selmi M, Rovai D, Mari M, Fischetti R, Pozio E. 2015. Trichinellosis outbreak caused by meat from a wild boar hunted in an Italian region considered to be at negligible risk for Trichinella. Zoonoses and Public Health, 62, 285-291.

28. Garbarino C, Interisano M, Chiatante A, Marucci G, Merli E, Arrigoni N, Cammi G, Ricchi M, Tonanzi D, Tamba M, La Rosa G, Pozio E. 2017. Trichinella spiralis a new alien parasite in Italy and the increased risk of infection for domestic and wild swine. Veterinary Parasitology, 246, 1-4.

29. Gómez-Morales MA, Ludovisi A, Amati M, Blaga R, Zivojinovic M, Ribicich M, Pozio E. 2012. A distinctive Western blot pattern to recognize Trichinella infections in humans and pig. International Journal for Parasitology, 42(11), 1017-1023.

30. Gómez-Morales MA, Ludovisi A, Amati M, Cherchi S, Pezzotti P, Pozio E. 2008. Validation of an enzyme-linked immunosorbent assay for diagnosis of human trichinellosis. Clinical Vaccine and Immunology, 15(11), 1723-1729.

31. Gottstein B, Pozio E, Nöckler K. 2009. Epidemiology, diagnosis, treatment, and control of trichinellosis. Clinical Microbiological Reviews, 22(1), 127-145.

32. International Classification of Diseases. 2018. Ninth Revision, Clinical Modification. Available from http://www.cdc.gov/nchs/ icd/icd9cm.htm. Accessed 29 November 2018.

33. Kociecka W. 2001. Trichinellosis in Poland during recent years (1996-1999). Wiadomosci Parazytologiczne, 47(2), 237-238.

34. La Rosa G, Vallée I, Marucci G, Casabianca F, Bandino E, Galati F, Boireau P, Pozio E. 2018. Multilocus genotype analysis outlines distinct histories for Trichinella britovi in the neighboring Mediterranean islands of Corsica and Sardinia. Parasite and Vectors, 11(1), 353.

35. Murrell KD, Pozio E. 2011. Worldwide occurrence and impact of human trichinellosis, 1986-2009. Emerging Infectious Diseases, 17(12), 2194-2202.

36. Petkova S, Mihov L, Vutova K, Tsenov I, La Rosa G, Pozio E. 2008. Epidemiological and clinical patterns of trichinellosis in Bulgaria from 1995 to 2002. Parasite, 15(1), 86-88.

37. Pozio E. 2015. Trichinella spp. imported with live animals and meat. Veterinary Parasitology, 213(1-2), 46-55.

38. Pozio E, La Rosa G. 1998. Short report: identification of the likely etiologic agent of human trichinellosis in Sicily (Italy) between 1933 and 1946. American Journal of Tropical Medicine and Hygiene, 59(6), 906-907.

39. Pozio E, La Rosa G, Gomez Morales MA. 2001. Epidemiology of human and animal trichinellosis in Italy since its discovery in 1887. Parasite, 8(2), 106-108.

40. Pozio E, Cossu P, Marucci G, Amati M, Ludovisi A, Gomez Morales MA, La Rosa G, Firinu T. 2009. The birth of a Trichinella britovi focus on the Mediterranean island of Sardinia (Italy). Veterinary Parasitology, 159(3-4), 361-363.

41. Pozio E, Marucci G. 2003. Trichinella-infected pork products: a dangerous gift. Trends in Parasitology, 19, 338.

42. Pozio E, Mesina P, Sechi F, Pira M, Liciardi M, Cossu P, Marucci G, Garippa G, Firinu A. 2006. Human outbreak of trichinellosis in the Mediterranean island of Sardinia, Italy. Veterinary Parasitology, 140(1-2), 177-180.

43. Romano F, Motta A, Melino M, Negro M, Gavotto G, Decasteli L, Careddu E, Bianchi C, Bianchi DM, Pozio E. 2011. Investigation on a focus of human trichinellosis revealed by an atypical clinical case: after wild-boar (Sus scrofa) pork consumption in northern Italy. Parasite, 18(1), 85-87.

44. Turiac IA, Cappelli MG, Olivieri R, Angelillis R, Martinelli D, Prato R, Fortunato F. 2017. Trichinellosis outbreak due to wild boar meat consumption in southern Italy. Parasites and Vectors, 10(1), 107.

45. Tuttitalia. 2018. https://www.tuttitalia.it/statistiche/cittadinistranieri/romania/. Accessed 29 November 2018. 
Cite this article as: Pozio E, Ludovisi A, Pezzotti P, Bruschi F \& Gómez-Morales MÁ. 2019. Retrospective analysis of hospital discharge records for cases of trichinellosis does not allow evaluation of disease burden in Italy. Parasite 26, 42.

\section{O PARASTE}

Reviews, articles and short notes may be submitted. Fields include, but are not limited to: general, medical and veterinary parasitology; morphology, including ultrastructure; parasite systematics, including entomology, acarology, helminthology and protistology, and molecular analyses; molecular biology and biochemistry; immunology of parasitic diseases; host-parasite relationships; ecology and life history of parasites; epidemiology; therapeutics; new diagnostic tools.

All papers in Parasite are published in English. Manuscripts should have a broad interest and must not have been published or submitted elsewhere. No limit is imposed on the length of manuscripts.

Parasite (open-access) continues Parasite (print and online editions, 1994-2012) and Annales de Parasitologie Humaine et Comparée (1923-1993) and is the official journal of the Société Française de Parasitologie. 